\title{
The Safety Transportation of Bulk Solid Cargoes
}

\author{
Jingguo Yuan \\ Department of Navigational Technology, Tianjin Maritime College, Tianjin, 300350, China \\ email: yjg3024@126.com
}

Keywords: solid bulk cargoes, weight distribution, ship stability, liquidation-prone cargo

\begin{abstract}
The solid bulk cargo transportation plays an important role in the carriage of goods by sea. Bulk cargo is any cargo that is transported in a loose form without any packaging in large quantities. Solid bulk cargo includes grain, ore, coal etc. Solid bulk cargo has some inherit natures such as having high density, liable to raise dust, liable to frost, liable to emit harmful gases, liable to liquefy, possessing chemical hazards. Solid bulk cargo is usually carried by bulk carriers which are very big in displacement and have no cargo on deck. Particular caution should be taken to ensure safe transportation of solid bulk cargo. Some dangers exist in the solid bulk cargo transporting process. The risk existing in the transportation of solid bulk cargo and its countermeasures are discussed in this paper.
\end{abstract}

\section{Introduction}

At present, the global economy is becoming more integrated and the shipping industry is developing rapidly, more and more goods are transported by sea in the world trade. Bulk cargo is any cargo that is transported in a loose form without any packaging in large quantities. There are millions tons of bulk cargo transported by sea each year. During its transportation, danger may emerge in some cases. For example, unreasonable cargo weight distribution will cause damage to ship structure; ship's stability will decrease or even cause ship capsize when cargo shift happened during the voyage; some solid bulk cargo will release harmful or combustible gases during its transporting process; the ship's hold bottom may be destroyed during cargo loading and unloading operation; solid bulk cargo may be soaked by sweat in the hold during the voyage. In order to ensure the safety, efficient and fast delivery of solid cargo in bulk, it is very important to know the risk in solid bulk cargo transportation and how to deal with these risks.

\section{To Ensure the Reasonable Weight Distribution and Avoid Damage to Ship Structure}

As the main mode of transportation of goods, ships take a large percentage. Bulk carriers have large gross tonnage [1] and do not load cargo on deck. If the cargo is not evenly distributed in each cargo hold of a bulk carrier, the ship will bend vertically and we call it hogging or sagging. In a small section of the hull, the opposite ends of the ship bear equal and opposite shear forces, so the section of the hull will have vertical relative displacement, which is called shear deformation. In the case of uneven weight distribution of the ship, the local strength may be too large, resulting in excessive local shear force, which can cause cracks and even tear in the ship's steel plates in extreme cases. When the cargo weight distribution on the ship is not reasonable, the structure of the ship will be damaged, thus an accident will occur. Especially when loads are distributed unevenly along the ship' length, the longitudinal strength requirements are not achieved, i.e. the hull longitudinal force exceeds longitudinal strength limit, in that condition, excessive hogging or sagging [2] will happen, then the ship's longitudinal strength members (such as deck, keel) will subject to permanent deformation or damage.

For the risk resulted from damage of ship structure because of loads distributed unevenly, we can adjust ship' ballast water to make sure the ships loads distributed evenly along the ship's length. We can determine the weight distribution of each hold according to the following 1-4 points, and attach importance to the following 5-7 points:

(1) To determine the weight of cargo for solid bulk cargo of each cargo hold, it is mainly 
required to consider the strength, stability, and draught of the ship. According to the recommendation in the ship's parameter, the weight of each hold can be allocated.

(2) The weight of each cargo hold is divided according to the capacity of the holds, and the value of the cargo weight is guaranteed to be the same as the value of the cargo allowed.

(3) The tonnage of each hold shall be determined by the loading instrument.

(4) To meet the requirements of International Association Classification Society for maximum load and minimum load.

(5) With respect to high density solid bulk loading, special attention should be paid to the distribution of weight, in order to avoid too much stress, meanwhile the improper distribution of goods is likely to cause excessive compression deformation on the compressed parts and even the whole hull structure. On the other hand, high density solid bulk cargo can cause heavy impact on the ship' bottom.

(6) We should supervise loading and unloading workers to adjust the nozzle position of loading or unloading machine so as to keep the ship upright, even if there is a short time of list, the angle of list should not exceed $3^{\circ}$. On the other hand, to do that can reduce the trimming workload.

(7) We should carry out loading and unloading operation in strict accordance with the loading and unloading plan, and should pay close attention to the ship's draft. Furthermore we should timely adjust the cargo loading speed and the speed of ballast water discharging to maintain a balance, so as not to affect the ship's stability.

\section{Guarantee the Stability of the Ship during the Voyage.}

During the voyage, the ship will subject to the force of wind and sea, and the ship experiences dynamic rolling, pitching, yawing, swaying, surging, heaving [3] which can cause the ship sailing movements complex. There is big sea in the ocean even there is no wind. So the ship should have sufficient stability to resist all kinds of bad weather at sea, if the ship's stability is insufficient or lose, it will be very dangerous such as ship capsizing. Bulk carriers are checked about their stability before departure, the ship in port should satisfy the stability requirement. But due to the structure of the bulk carrier and the characteristics of the bulk cargoes, bulk carriers may lose stability due to cargo shift.

Trimming the hold is a flat operation for some goods or all goods in the cargo hold. Bulk cargoes include coal, ore and other goods, such goods may automatically become steadfast during the voyage because of bumps, vibration of the ship. In that condition the goods will fill every corner of the hold, the full hold at the beginning will be no longer full. If the trimming work has not been done well, the hold will be no longer full, and the cargo in the hold will most probably begin to generate displacement during the voyage. If this thing happened, the stability of the ship will decrease or lose, even the ship capsizes.

In addition, there is a class of goods called liquidation-prone cargo, which are composed of a mixture of finer particles, including concentrate, coal, and goods with similar physical properties. The potential danger of these goods is that when their water content exceeds their Transportable Moisture Limit, the goods will be displaced due to fluidization. "Fluidized" refers to the material in appearance, at the time of shipment is dry, but still contains a large quantity of moisture. Due to turbulence, vibration of the ship during the voyage, the water contained in the cargo seeps gradually on the surface of the cargo. The cargo whose surface has been fluidized will flow to one side when the ship swings, but it will not flow back completely when the ship is rolling back, so that the ship will gradually incline and even overturn. If the ship is loaded with pyrite and zinc sulfide, the fluidization is likely to happen.

In view of the risks caused by the loss of stability during the voyage, the following precautions should be taken:

(1) In the loading process, reasonable trimming shall be conducted and checked according to the nature of the goods and the angle of repose. As an effective measure to reduce the displacement of cargo in the hold, the trimming operation plays an important role for ships whose length is shorter than $100 \mathrm{~m}$. 
For a multi-deck ship, if the cargo is only loaded into the bottom of the hold, the cargo should be fully trimmed so that the weight of the cargo is equally distributed in the bottom of the hold. When loading bulk cargo in the tween deck [4], the hatch cover should be closed if the loading data is clearly shown that opening hatch cover will result the overloading of the ship' bottom. The goods should be properly trimmed.

For the non-viscous bulk cargo whose repose angle is greater than 35 degrees, special attention should be paid to avoid the formation of wide and steep gaps between the exterior and bulkhead of the flat surface. The inclination angle of the cargo surface should be less than its angle of repose.

(2) The following points should be noted for liquidation-prone cargo:

1) The hold loading cargo which may liquefy [5] should be able to prevent the inflow of any liquid, i.e. the cargo hold should be watertight.

2) Liquidation-prone cargo are usually not suitable to be stowed in the same hold with the wet cargo because they contain water.

3) So far as possible, stow the liquidation-prone cargo together because in that condition, once the cargo liquefied, the harm to the ship's stability can be reduced to the minimum.

4) Some dangerous goods can have harmful chemical reactions and produce flammable gases. Therefore, such dangerous goods should be effectively isolated from the liquidation-prone cargo.

\section{Chemical Reactions of Bulk Goods, can Produce Combustible or Explosive Gases and Poisonous Gases which may Cause Casualties or Ship Accidents}

The danger can happen to the strength, the structure, stability of the ship itself in the process of transportation. There will also be some dangers to the ships in the process of loading and unloading cargo. The goods itself may react and cause some dangerous accidents. Chemical dangerous goods refer to cargoes resulting danger during the transportation due to their own chemical nature. Such goods are already listed in the "International maritime dangerous goods code", such goods is considered as dangerous goods either in packaging form or bulk form because of the chemical nature of itself and further more with the same classification number. For example, the sulfur belongs to the flammable solid, it is easy to be ignited by external fire sources such as spark and flame, easy to burn; waste aluminum, zinc slag, silicon iron and so on, they will produce combustible gas once encounter bright fire or spark, etc., so they are easy to burn or explode.

Concerning chemical dangerous goods, the chemical reaction should be fully considered because the safety of the ship, goods and personnel may be threatened. We can take some countermeasures as follow:

(1) The same type of cargo should be stowed in the same cargo hold and the compatibility should be noted.

(2) When loading the cargo which can release flammable gas, the cargo should be stowed away from heat source and fire source and be kept as dry as possible. Ensure the ship electrical appliances and cables are in good condition; Materials that are readily emitting gases or vapors which can mix with the atmosphere so as to form explosive mixture should be stowed in the hold which has mechanical ventilation.

(3) For the oxidants, such as aluminum nitrate and other goods, they should be kept away from heat source and fire source, so as to keep the cargo as cool and dry as possible and should be separated from the flammable material.

(4) When loading radioactive material, leakage of the cargo hold is not allowed, and these cargoes should not be stowed with other cargoes.

(5)When loading the corrosive goods, the holds should be clean and dry, the goods are not allowed to leak into the slop tank and adjacent compartment.

\section{Damage to the Ship's Strength during Loading and Unloading}

In the process of loading and unloading of solid bulk cargo, grab and conveyor equipment is frequently used. Solid bulk carriers are generally large, cargo hold is usually very deep. Cargo from 
grab or the conveyor belt fall into the cargo hold bottom. Because of the big height of the cargo hold, the cargo dropped on to the hold bottom and cause the hold bottom deform. If this condition continues day by day, the strength of the cargo hold bottom is severely decreased. So in the process of loading operation, such loading manner should be avoided. The height of grab bucket and the conveyor belt should be lowered at the beginning of loading to minimize the impact on the bottom. Furthermore the deforming condition of the bottom plate should be frequently checked, once severe deformation is found, repair and maintenance should be done.

\section{Cargo Management when Underway}

During the transportation of solid bulk cargo, the following aspects should be carried out to ensure the quality of goods and ship safety.

1) To measure the temperature and humidity in the hold regularly and ventilate properly so as to prevent the sweat affecting the quality of the goods or reacting with the cargo, and eventually threaten the safety of the ship.

2) For goods that are liable to generate harmful gases, ventilation should be conducted at the right time to discharge the harmful gases in the cargo hold.

3) Check the condition of the goods in the cargo hold and determine whether there is any abnormality. If necessary, appropriate measures should be taken.

4) To measure the depth of the slop periodically, discharge the slop in the slop tank in time, and prevent the slop from soaking the cargo in the hold.

5)Ship' course and speed should be adjusted during the voyage, make the ship's bow form an angle of $20^{\circ}$ to $30^{\circ}$ to the wind direction and wave set so as to reduce the impact force of the sea water. To do so can also reduce the vibration and swing of the ship. When encounter long swell in the sea, especially the surge wavelength is close to the ship's length, we should keep the ship and swell with a certain angle and avoid ship sailing cross between the crest swell and trough swell. Navigating across the crest swell and trough swell will lead to frequent hogging and sagging, eventually the ship's longitudinal strength is reduced, or even the ship will break in the middle of the ship.

\section{Conclusion}

In conclusion, when the large bulk carriers is transporting solid bulk cargoes, danger may appear on each link. We should take ship's strength, ship's stability, ship’s trimming work when loading cargo, cargo's nature, cargo handling equipment into consideration to ensure the safe transportation of cargo. We should protect the solid bulk cargo from being soaked by the ship' sweat in hold; and we should keep the vessel watertight to prevent the sea water entering the cargo hold; we should ventilate the cargo properly to keep the solid bulk cargo being dry. In addition to the aspects listed in this paper, some other potential dangers with small probability should also be cared about. In a word, seafarers should do everything to prevent the potential risk from happening.

\section{Reference}

[1] Xu Bangzhen,Tian Baijun. Cargo Transportation on Sea, [M] Dalian. Dalian Maritime University press. 2012.8

[2] Shen Yuru. Ship Cargo Transportation [M] Dalian. Dalian Maritime University press. 2006.12

[3] Zhao Yuelin. Ship Maneuvering and Collision Avoidance, [M] Dalian. Dalian Maritime University press. 2012.8

[4] Shen Jiang, Ding Zihua, Jiang Chaoyan. Nautical English, [M] Dalian. Dalian Maritime University press. 2016.11

[5] Ma Changjian,issue. The Safety Status and Countermeasures of Solid Bulk Cargo 
Transportation Which May Liquefy, Shipping Management, [J] Aug 2012 